REVISTA DE DERECHO UNED, NÚM. 17, 2015

\title{
EL DERECHO A UN RECURSO EFECTIVO. UNA APROXIMACIÓN TEÓRICO-CONCEPTUAL
}

\author{
THE RIGHT TO AN EFFECTIVE REMEDY. \\ A THEORETICAL AND CONCEPTUAL APPROXIMATION
}

\author{
Martha Elba Dávila Pérez
}

Doctoranda de la UNED

Resumen: Para que un derecho sea respetado no basta que se encuentre contenido en una constitución, legislación o declaración de derechos, sino que es necesario un marco legal de protección a esos derechos y libertades que incluya los instrumentos para hacerlos efectivos. Así, la correcta instrumentación del Derecho a un Recurso Efectivo resulta de gran trascendencia en cuanto constriñe al Estado a desarrollar todas aquellas condiciones para asegurar una adecuada defensa de los ciudadanos, cuyos derechos pueden ser afectados por una decisión del poder público. El presente trabajo analiza el Derecho a un Recurso Efectivo desde distintas aristas: como derivación de las obligación de adoptar disposiciones de orden interno a fin de hacer respetar los derechos humanos; la diferencia en la formulación consagrada en la Convención Americana sobre Derechos Humanos y el Pacto Internacional de Derechos Civiles y Políticos; así como su desarrollo histórico y conceptual a fin de estar en posibilidades de comprender su importancia.

Abstract: For a right to be respected it is not enough to be contained in a constitution, legislation or declaration of rights, but is required a legal framework of protection of those rights and freedoms including instruments to make them effective. In this matter, the correct instrumentation of the Right to an Effective Resource has a great significance, as it constrains the State to develop all those conditions to ensure a proper defense of the citizens, whose rights could be af- 
fected by a public power decision. This paper analyzes the right to an effective resource from different points of view: like a derivation of the obligations to adopt domestic arrangements in order to respect human right, the difference in the consecrated formulation in the American Convention about Human Rights and the International Covenant on Civil and Political Rights, as well as its historical and conceptual development in order to be able to understand its importance.

Palabras clave: Derecho a un Recurso Efectivo, Convención Americana sobre Derechos Humanos, Pacto Internacional de Derechos Civiles y Políticos, mecanismos de protección de Derechos Humanos.

Keywords: The Right to an Effective Resource, American Convention about Human Rights, International Covenant of Civil and Political Rights, protective mechanisms of Human Rights.

Recepción original: 16/06/2015

Aceptación original: 14/07/2015

Sumario: I. El Derecho a un Recurso Efectivo como obligación general derivada de la adopción de un tratado internacional de derechos humanos. II. La consagración del Derecho a un Recurso Efectivo en el Sistema Interamericano de protección de Derechos Humanos. III. El Derecho a un Recurso Efectivo en otros sistemas de Protección de Derechos Humanos. IV. Estudio comparativo de las disposiciones internacionales en materia del Derecho a un Recurso Efectivo. IV. A. Desde el punto de vista de su consagración: como derecho humano o como obligación a cargo del Estado. IV. B. Desde el punto de vista del rango de cobertura del recurso. IV. C. Desde el punto de vista de su autonomía. V. Trayecto histórico-convencional del Derecho a un Recurso Efectivo. VI. Conceptualización y caracterización del Derecho a un Recurso Efectivo. VI. A. Como derecho humano autónomo de tipo público subjetivo. VI. B. Como instrumento para hacer efectivos otros derechos. VI. C. Como especie dentro del género de los derechos de seguridad jurídica. VII. Conclusiones.

\section{EL DERECHO A UN RECURSO EFECTIVO COMO OBLIGACIÓN GENERAL DERIVADA DE LA ADOPCIÓN DE UN TRATADO INTERNACIONAL DE DERECHOS HUMANOS}

Los artículos $1 .^{\circ}$ y $2 .^{\circ}$ de la Convención Americana sobre Derechos Humanos (correlativos del artículo $2 .^{\circ}$ del Pacto Internacional de Derechos Civiles y Políticos), prevén las obligaciones de respetar los de- 
rechos consagrados en los diversos instrumentos internacionales de Derechos Humanos, garantizar su pleno y libre ejercicio, así como adoptar medidas internas para hacerlos efectivos. Esta obligación de adoptar disposiciones de derecho interno hace necesario que el Estado adecue su normativa interna a las disposiciones convencionales con el fin de posibilitar el cumplimiento de las obligaciones convenidas en relación con cada derecho humano protegido por la Convención. Se cumple esta obligación general tanto con la expedición de normas, como mediante la revisión o derogación de leyes o prácticas que sean contrarias a los Derechos Humanos y con el desarrollo de las que resulten conducentes para la observancia efectiva de los derechos y libertades. El Estado debe establecer todo tipo de medidas para suprimir las prácticas de cualquier naturaleza que entrañen una violación a los Derechos Humanos.

Sobre este tema se pronunció el Comité de Derechos Humanos de las Naciones Unidas en la Observación General 31. Sostuvo que la obligación de adoptar las medidas para hacer efectivos los derechos consagrados en el Pacto implica que los Estados deban realizar los cambios de derecho y prácticas internas que sean necesarios para garantizar su conformidad con éste, obligación que no está sometida a condiciones, es de efecto inmediato y su incumplimiento no puede estar justificado por consideraciones políticas, sociales, culturales o económicas ${ }^{1}$.

Esta obligación de adecuar el derecho interno a las disposiciones convencionales cobra gran relevancia en Estados que, como México, establecen como principio jurídico máximo la supremacía constitucional (artículo 133 Constitucional previo a la reforma sobre Derechos Humanos), lo cual implica, en la realidad, una resistencia al deber de hacer efectivos los derechos consagrados en los pactos internacionales. El Estado Mexicano, como muchos otros, utilizaba frecuentemente un doble discurso pues aunque hacia el exterior era promotor de la adopción de tratados internacionales, éstos representaban letra muerta hacia el interior.

Ante el incumplimiento de adecuar el derecho interno, el Poder Judicial representa la última oportunidad para remediar una violación, puesto que los jueces, en un ejercicio de control de convenciona-

${ }^{1}$ Comité de Derechos Económicos, Sociales y Culturales de la Naciones Unidas, La Índole De La Obligación Jurídica General Impuesta a Los Estados Partes En El Pacto (Artículo 2 Del Pacto Internacional De Derechos Civiles Y Politicos, Observación General número 31 de 2004, 80o período de sesiones, U. N. Doc. HRI/gen/1/Rev.7 at 225, párrafo 15 . 
lidad, se encuentran obligados a aplicar la normatividad convencional y jurisprudencial de la Corte Interamericana de Derechos Humanos. Este ejercicio hace posible interpretar las disposiciones nacionales conforme al Pacto de San José y el corpus juris interamericano, así como no aplicar aquellas que contravengan de manera absoluta la Convención, evitando que el Estado resulte internacionalmente responsable por violar compromisos adquiridos en materia de Derechos Humanos ${ }^{2}$.

EL Juez Cançado Trindade, al analizar el deber general contenido en el artículo 1.1 de la Convención -de respetar y hacer respetar sin discriminación alguna los derechos protegidos-, concluye que la obligación de adoptar las medidas para hacer efectivos los derechos humanos no puede tener meramente el carácter de accesorio de las disposiciones relativas a los derechos convencionalmente consagrados, sino que tiene significado en sí mismo. Considera que no se incumple con la normativa convencional solamente cuando se ha comprobado la existencia de una violación a un derecho específico, sino también cuando se deja de cumplir uno de los deberes generales y que este incumplimiento puede acarrear nuevas víctimas, generando per se violaciones adicionales, sin que sea necesario relacionarlas con los derechos originalmente vulnerados ${ }^{3}$.

En la jurisprudencia constante del Sistema Interamericano se ha sostenido la relación existente entre el derecho a un recurso efectivo con las obligaciones generales contenidas en los artículos 1.1 y 2, ambos de la Convención de garantizar el libre y pleno ejercicio de los Derechos Humanos y de adoptar disposiciones en el orden interno para hacerlos efectivos. Esta asociación se hace patente en la sentencia del caso Castañeda Gutman vs. México ${ }^{4}$, en la que la Corte declaró infundado la violación al derecho sustancial alegado por el peticionario-derecho a votar y ser votado -, pero fundada la violación de no proveer los recursos efectivos y, por ello, la obligación de garantía

${ }^{2}$ FERRER MAC-GREGOR, Eduardo y PELAYO MOLLER, Carlos María. «La obligación de «respetar» y «garantizar» los derechos humanos a la luz de la jurisprudencia de la Corte Interamericana, Análisis del artículo $1 .^{\circ}$ del pacto de San José como fuente convencional del derecho procesal constitucional mexicano» en Estudios constitucionales, Año 10, N. ${ }^{\circ}$ 2, Centro de Estudios Constitucionales de Chile, Universidad de Talca, Santiago, 2012, págs. 141-192, en http://www.revistasconstitucionales.unam.mx/pdf/3/art/art4.pdf.

${ }^{3}$ Corte Interamericana de Derechos Humanos, Masacre de Mapiripán vs. Colombia, sentencia de 15 de septiembre de 2005, serie c, número 134, voto razonado del Juez CANÇADO TRINDADE, Antonio Augusto, párrafo 3.

${ }^{4}$ Corte Interamericana de Derechos Humanos, Caso Castañeda Gutman Vs. Estados Unidos Mexicanos (Excepciones Preliminares, Fondo, Reparaciones y Costas), sentencia de 6 de agosto de 2008, serie C, número 184, párrafos 101-103. 
prevista en el párrafo 1.1 de la Convención. La violación cometida por el Estado Mexicano de no proporcionar un recurso efectivo para remediar las violaciones a un derecho político electoral le ocasionó también ser condenado por la inobservancia al deber general de adecuación del derecho interno. En su aspecto positivo la obligación de adecuación se traduce en la adopción de las medidas de cualquier orden para hacer cumplir los derechos consagrados en la Convención Americana sobre Derechos Humanos, lo que el Estado Mexicano incumplió.

El principal obligado en el cumplimiento de la modificación del orden interno es el Poder Legislativo. Conforme al principio de la división de poderes es a éste a quien corresponde naturalmente la formación de las leyes. En consecuencia, el artículo 25 de la Convención Americana tiene efectos vis-à-vis actos del Poder Legislativo de los Estados, pues es necesaria la incorporación de un recurso efectivo en el derecho interno de los Estados Partes, lo que constituye una obligación directa a cargo del órgano legislativo. De incumplir esta disposición, el Estado en su conjunto es responsable por violentar la Convención ${ }^{5}$. Es en este tenor que cobran gran relieve los principios generales del derecho internacional que postulan que las obligaciones derivadas de los instrumentos internacionales deben ser cumplidas de buena fe y no puede invocarse para su incumplimiento disposiciones en contrario del derecho interno ${ }^{6}$.

En la Opinión Consultiva (en adelante OC) 14/94, al pronunciarse sobre la responsabilidad internacional por expedición y aplicación de leyes violatorias de la convención, la Corte Interamericana de Derechos Humanos expresó que la obligación de dictar las medidas que fueren necesarias para hacer efectivos los derechos y libertades reconocidos en la Convención comprende la de no dictarlas cuando ellas conduzcan a su violación y que "Son muchas las maneras como un Estado puede violar un tratado internacional y, específicamente, la Convención. En este último caso, puede hacerlo, por ejemplo, omitiendo dictar las normas a que está obligado por el artículo 2. También, por supuesto, dictando disposiciones que no estén en conformidad con lo que de él exigen sus obligaciones dentro de la Convención ${ }^{7}$. En esta opinión, la Corte reiteró lo sostenido en la di-

${ }^{5}$ Cfr. Corte Interamericana de Derechos Humanos, caso Genie Lacayo versus Nicaragua (Solicitud de Revisión de la Sentencia de Fondo, Reparaciones y Costas), sentencia de 13 de septiembre de 1997, serie C, número 45, voto disidente del Juez CANÇADO TRINDADE, Antonio Augusto, párrafos 18 a 20.

${ }^{6}$ Convención de Viena sobre el Derecho de los Tratados de 1969: artículos 26 y 27.

${ }^{7}$ Corte Interamericana de Derechos Humanos, Responsabilidad Internacional por expedición y aplicación de leyes violatorias de la Convención (Arts. 1 y 2 Convención 
versa OC-13/93, en el sentido de que la Comisión tiene competencia, en términos de las los artículos 41 y 42 de la Convención, para calificar cualquier norma del derecho interno de un Estado Parte como violatoria de las obligaciones que éste ha asumido al ratificarla o adherirse a ella. Como consecuencia de esta calificación, la Comisión puede recomendar al Estado la derogación o reforma de la norma violatoria y para ello es suficiente que tal norma haya llegado por cualquier medio a su conocimiento aun y cuando no haya sido aplicada en un caso concreto ${ }^{8}$. La Corte también ha apuntado, tanto en uso de su facultad contenciosa como en la consultiva, que el deber de un Estado de introducir en su derecho interno las modificaciones necesarias para asegurar la ejecución de las obligaciones internacionales asumidas constituye una norma consuetudinaria del derecho internacional de los Derechos Humanos y que la inexistencia de un recurso efectivo contra las violaciones a los derechos reconocidos por la Convención constituye en sí misma una trasgresión ${ }^{9}$.

\section{LA CONSAGRACIÓN DEL DERECHO A UN RECURSO EFECTIVO EN EL SISTEMA INTERAMERICANO DE PROTECCIÓN DE DERECHOS HUMANOS}

El derecho a un recurso efectivo se encuentra contenido en diversos instrumentos internacionales, tanto del sistema universal como de los sistemas regionales. Los más importantes en el sistema interamericano de Derechos Humanos son la Declaración Americana de los

Americana Sobre Derechos Humanos), Opinión Consultiva OC-14/94 de 9 de diciembre de 1994, serie A, número 14.párrafos 36 a 39.

${ }^{8}$ En la Opinión Consultiva OC-14/94 la Corte, con relación a su competencia contenciosa, hizo una diferenciación entre las normas que llamó de aplicación inmediata y las que no tienen esa característica. Las primeras las definió como aquellas cuya sola entrada en vigor afectan a las personas sujetas a jurisdicción del Estado. Las segundas son las que requieren un acto posterior. La Corte indicó que en el caso de que la ley no sea de aplicación inmediata y no haya sido aún aplicada a un caso concreto, la Comisión no puede comparecer ante la Corte para someter un caso contra el Estado con base en la sola emisión de la ley, puesto que no representa, per se, violación de los derechos humanos. Caso contrario en las leyes de aplicación inmediata, la vulneración, individual o colectiva, de derechos humanos se produce por el solo hecho de su expedición (Por ejemplo norma que despojara de algunos de sus derechos a una parte de la población, con motivo de su raza, automáticamente lesiona a todos los individuos de esa raza, expresó). La razón de esta diferenciación radica en que la jurisdicción contenciosa de la Corte se ejerce con la finalidad de proteger los derechos y libertades de personas determinadas y no con la de resolver casos abstractos. (Supra Ídem, párrafos 40 a 49).

${ }^{9}$ Corte Interamericana de Derechos Humanos, Garantías Judiciales en Estados de Emergencia (Arts. 27.1, 25 y 8 de la Convención Americana Sobre Derechos Humanos), opinión consultiva OC-9/87, de 6 de octubre de 1987, serie A, número 9, párrafo 24. 
Derechos y Deberes del Hombre (1948) - artículo XVIII y, en forma relacionada, los artículos V y XXVI que establecen el derecho a la protección de la ley y las garantías judiciales- ${ }^{10}$ y la Convención Americana sobre Derechos Humanos (1969) cuyo artículo 25 establece el derecho a la protección judicial en el que se encuentra contenido el derecho a un recurso efectivo. ${ }^{11}$

Existen también dos convenciones especializadas que, de acuerdo a la materia específica que tratan, consagran la obligación a cargo del Estado el establecimiento de un recurso para efecto de proteger un derecho específico. El artículo 8 de la Convención Interamericana para prevenir y sancionar la tortura (1985) establece la obligación a cargo de los Estados Partes de garantizar a toda persona que denuncie haber sido sometida a tortura, el derecho a que el caso sea examinado imparcialmente, investigación que debe proceder oficiosamente y a iniciar el procedimiento penal. También el artículo 4 de la Convención Interamericana para prevenir, sancionar y erradicar la violencia contra la mujer (1994) prevé el derecho de la mujer a la protec-

${ }^{10}$ Declaración Americana de los Derechos y Deberes del Hombre:

Artículo XVIII. Toda persona puede ocurrir a los tribunales para hacer valer sus derechos. Asimismo debe disponer de un procedimiento sencillo y breve por el cual la justicia lo ampare contra actos de la autoridad que violen, en perjuicio suyo, alguno de los derechos fundamentales consagrados constitucionalmente.

Artículo V.

Toda persona tiene derecho a la protección de la Ley contra los ataques abusivos a su honra, a su reputación y a su vida privada y familiar.

Artículo XXVI.

Se presume que todo acusado es inocente, hasta que se pruebe que es culpable. Toda persona acusada de delito tiene derecho a ser oída en forma imparcial y pública, a ser juzgada por tribunales anteriormente establecidos de acuerdo con leyes preexistentes y a que no se le imponga penas crueles, infamantes o inusitadas.

${ }^{11}$ Convención Americana sobre Derechos Humanos:

Artículo 25. Protección Judicial

1. Toda persona tiene derecho a un recurso sencillo y rápido o a cualquier otro recurso efectivo ante los jueces o tribunales competentes, que la ampare contra actos que violen sus derechos fundamentales reconocidos por la Constitución, la ley o la presente Convención, aun cuando tal violación sea cometida por personas que actúen en ejercicio de sus funciones oficiales.

2. Los Estados Partes se comprometen:

a) a garantizar que la autoridad competente prevista por el sistema legal del Estado decidirá sobre los derechos de toda persona que interponga tal recurso;

b) a desarrollar las posibilidades de recurso judicial, y

c) a garantizar el cumplimiento, por las autoridades competentes, de toda decisión en que se haya estimado procedente el recurso. 
ción de los Derechos Humanos y libertades consagradas en instrumentos internacionales, entre otros, el derecho a un recurso sencillo y rápido que la ampare contra actos que violen sus derechos.

\section{EL DERECHO A UN RECURSO EFECTIVO EN OTROS SISTEMAS DE PROTECCIÓN DE DERECHOS HUMANOS}

Tanto en el Sistema de las Naciones Unidas, como en el Europeo y en el Africano, se encuentra consagrado el derecho a un recurso efectivo. En el Sistema Universal de Derechos Humanos se ubica en la Declaración Universal de Derechos Humanos y en el Pacto Internacional de Derechos Civiles y Políticos. El artículo 8 de la Declaración Universal de Derechos Humanos (1948) establece el derecho de toda persona a un recurso efectivo que la ampare contra actos que violen sus derechos fundamentales reconocidos por la constitución o por la ley. En forma relacionada el artículo 7 de la misma declaración prescribe el derecho de igualdad ante la ley, así como de igual protección de la ley y los artículos 10 y 11.1 establecen el derecho de audiencia y la presunción de inocencia. En el Pacto Internacional de Derechos Civiles y Políticos ${ }^{12}$ el artículo 2.3. prevé la obligación de los Estados Partes de garantizar que toda persona cuyos derechos o libertadas hayan sido violados, puedan interponer un recurso efectivo ante la autoridad competente, judicial, administrativa, legislativa o cualquier otra, así como la de acatar las resoluciones recaídas a los recursos. En relación con este texto, los artículos 14 y 16 establecen el derecho de igualdad ante los tribunales, la garantía de audiencia y las garantías

12 Pacto Internacional de Derechos Civiles y Políticos:

Artículo 2.

3. Cada uno de los Estados Partes en el presente Pacto se compromete a garantizar que:

a) Toda persona cuyos derechos o libertades reconocidos en el presente Pacto hayan sido violados podrán interponer un recurso efectivo, aun cuando tal violación hubiera sido cometida por personas que actuaban en ejercicio de sus funciones oficiales;

b) La autoridad competente, judicial, administrativa o legislativa, o cualquiera otra autoridad competente prevista por el sistema legal del Estado, decidirá sobre los derechos de toda persona que interponga tal recurso y a desarrollar las posibilidades de recurso judicial;

c) Las autoridades competentes cumplirán toda decisión en que se hayan estimado procedente el recurso. 
judiciales, entre las que se encuentra la presunción de inocencia y la garantía de igualdad de protección ante la ley.

En el Convenio Europeo para la Protección de los Derechos Humanos y de las Libertades Fundamentales (1950), el artículo 13 establece el derecho a un recurso efectivo a toda persona cuyos derechos y libertades hayan sido violados. Asimismo, el artículo 6, párrafo 1, establece el derecho ser oído para la determinación de sus derechos civiles o sobre el fundamento de cualquier acusación en materia penal, mientras que los párrafos 2 y 3 establecen el derecho a la presunción de inocencia y las garantías judiciales, respectivamente.

Por último, el artículo 7 de la Carta Africana sobre Derechos Humanos y de los Pueblos (1981) dispone el derecho de todo individuo a que su caso sea visto, lo que implica el derecho de apelación, derecho a ser considerado inocente, derecho de defensa así como el derecho a ser juzgado en un plazo justo.

\section{ESTUDIO COMPARATIVO DE LAS DISPOSICIONES INTERNACIONALES EN MATERIA DEL DERECHO A UN RECURSO EFECTIVO}

Los artículos 2.3 del Pacto Internacional de Derechos Civiles y Políticos y 25.2 de la Convención Americana consagran el derecho a un recurso que proteja a los ciudadanos de las violaciones a sus Derechos Humanos con una estructura y contenido similares. Las dos disposiciones en análisis refieren que el recurso debe ser efectivo y amparar a la víctima de violaciones de los Derechos Humanos cometidas por autoridades públicas o por actos cometidos por sujetos privados. Establecen además, en primer lugar, la obligación de los Estados Partes de desarrollar recursos de carácter judicial (en los incisos b de ambas disposiciones); luego, la obligación a cargo de las autoridades que conocen de los recursos a pronunciarse sobre los derechos de los recurrentes (inciso b del artículo 2.3 del Pacto e inciso a del artículo 25.2 de la Convención Americana); y, por último, la obligación de las demás autoridades de cumplir con las decisiones que recaigan a raíz de los recursos (inciso c de ambos artículos).

Las diferencias existentes entre ambas disposiciones son substanciales y como consecuencia impactan en que la jurisprudencia emitida por el Comité de Derechos Civiles y Políticos (sistema universal) y por los órganos del sistema interamericano (Corte y Comisión) no sea siempre coincidente. 


\section{A. Desde el punto de vista de su consagración: como derecho humano o como obligación a cargo del Estado}

El primer párrafo del artículo 25 de la Convención consagra el derecho a un recurso efectivo como derecho subjetivo al señalar que «Toda persona tiene derecho a un recurso sencillo y rápido o a cualquier otro recurso efectivo ante los jueces o tribunales competentes». En cambio, en el Pacto Internacional de Derechos Civiles y Políticos no se hace referencia al recurso efectivo como un derecho, sino como una obligación del Estado «a garantizar que toda persona cuyos derechos o libertades reconocidos en el presente Pacto hayan sido violados podrán interponer un recurso efectivo». El artículo 2 que se refiere al derecho a un recurso efectivo se ubica en la Parte II, en el que se encuentran agrupados otros cuatro artículos referentes a la libre determinación de los pueblos, igualdad entre hombres y mujeres, el impacto de estados de emergencia y el principio pro homine en la interpretación de las disposiciones del Pacto; disposiciones que establecen obligaciones o principios generales, pero no hacen referencia a derechos subjetivos ${ }^{13}$.

El derecho a igual protección de la ley, consagrado en los artículos 14.1 y 26 del Pacto, contribuyen a paliar las diferencias del artículo 2.3 con el 25 de la Convención, puesto que al referirse que el concepto de protección de la ley incluye el derecho a recurrir a los tribunales para la protección de sus derechos.

\section{B. Desde el punto de vista del rango de cobertura del recurso}

Otra importante diferencia radica en el campo de cobertura del recurso, pues mientras que el artículo 2.3 del Pacto hace referencia a que el recurso tendrá la finalidad de proteger los derechos o libertades reconocidos por el mismo Pacto, el artículo 25 de la Convención Americana, en una forma más amplia, consagra que el recurso tendrá por objeto el amparar a la persona contra actos que violen sus derechos fundamentales reconocidos por la Constitución, la ley o la propia Convención ${ }^{14}$.

${ }^{13}$ O'DONNELL, Daniel. Derecho internacional de los derechos humanos, Tomo II, Oficina en Colombia del Alto Comisionado de las Naciones Unidas para los Derechos Humanos, Colombia, 2004, pág. 472.

${ }^{14}$ COURTIS, Christian. «El derecho a un recurso rápido, sencillo y efectivo frente a afectaciones colectivas de derechos humanos" en Revista Iberoamericana de Derecho Procesal Constitucional, número 5, Porrúa-Instituto Iberoamericano de Derecho Procesal Constitucional, México, 2006, págs. 33-65 en http://newnaildesigns.com/revistas/5/pdf/47_79.pdf 
Al igual que en el sistema universal, el Convenio Europeo para la Protección de los Derechos Humanos y las Libertades Fundamentales reconoce el derecho a un recurso efectivo a toda persona cuyos derechos y libertades reconocidos en el presente Convenio hayan sido violados, sin hacer referencia a los derechos reconocidos por el derecho interno. La Carta Africana sobre Derechos Humanos, por el contrario, se refiere a los derechos fundamentales reconocidos y garantizados por los convenios, leyes, ordenanzas y costumbres vigentes.

La Corte Interamericana de Derechos Humanos ha sostenido que el artículo 25.1 del Pacto de San José establece que los recursos judiciales deben proteger y velar «no sólo respecto de los derechos contenidos en la Convención» ${ }^{15}$, sino también de aquéllos que estén reconocidos por la Constitución o por la ley, criterio que se encuentra vinculado con la disposición contenida con el artículo 29.b) del Pacto de San José, que señala que éste consagra derechos mínimos susceptibles de ampliación por otras disposiciones convencionales y nacionales, las cuales la Convención Americana hace suyas al proporcionarles el mismo grado de garantía que otorga a los derechos que las que conforman.

El Juez Ferrer Mac Gregor considera que este aspecto resulta de gran importancia, ya que prevé que el derecho a un recurso efectivo debe aplicarse no únicamente respecto de los derechos contenidos en la Convención Americana, sino también de aquéllos que estén reconocidos por la Constitución o por las leyes nacionales. También expresa que, si bien este criterio se adoptó en la OC-9/87 al interpretar cuáles derechos no son susceptibles de suspensión en estado de emergencia, desde entonces, en pocas ocasiones ha sido utilizado por el Tribunal Interamericano y no ha sido desarrollado respecto a todas sus implicaciones ${ }^{16}$.

\section{C. Desde el punto de vista de su autonomía}

La última diferencia a la que se puede hacer referencia y, sin embargo, constituye una cuestión radical es la relativa a la autonomía de este derecho a nivel jurisprudencial. El Comité de Derechos Humanos de las Naciones Unidas ha considerado que únicamente existe vulne-

${ }^{15}$ Corte Interamericana de Derechos Humanos, Garantías Judiciales en Estados de Emergencia (Arts. 27.1, 25 y 8 de la Convención Americana Sobre Derechos Humanos), opinión consultiva OC-9/87, Ob. cit., párrafo 23.

${ }^{16}$ Corte Interamericana de Derechos Humanos, caso Liakat Ali Alibux vs. Surina$m e$, (Excepciones preliminares, fondo y reparaciones) sentencia de 30 de enero de 2014, serie C, número 276, voto concurrente del Juez FERRER MAC GREGOR, Eduardo, párrafo 46. 
ración al derecho a un recurso efectivo cuando existe una violación a algún otro de los derechos protegidos. Por el contrario, en el Sistema Interamericano de Derechos Humanos se ha recorrido un camino jurisprudencial por el que el derecho a un recurso efectivo ha alcanzado notas autónomas.

Esta distinción puede ser consecuencia de la diferencia en la formula adoptada en los artículos 2.3 del Pacto Internacional de Derechos Civiles y Políticos y 25.2 de la Convención Americana. Como se ha mencionado previamente, éste último prevé el recurso efectivo como un derecho subjetivo, mientras que en el Pacto se encuentra consagrado como obligación a cargo del Estado.

En varias resoluciones, el Comité de Derechos Humanos de las Naciones Unidas había sostenido que el derecho general a un recurso es accesorio y no puede ser invocado sino cuando ha quedado acreditada la violación de otro derecho consagrado por el Pacto Internacional de Derechos Civiles y Políticos. Sin embargo, esta línea interpretativa ha comenzado a cambiar. En la decisión adoptada en el caso Magaña contra Zaire en 1983, se consideró que las autoridades de este país habían violentado el contenido del artículo 25 del Pacto al incumplir la decisión de la instancia nacional que ordenó reintegrar a un funcionario a su puesto y, como consecuencia, consideró que la comprobada violación del artículo 2 del mismo hacía innecesario pronunciarse sobre las posibles violaciones de los artículos 14 y $26.6^{17}$. Posteriormente, el Comité ha otorgado gran importancia al artículo 2.3 como base de las recomendaciones que dirige a los Estados en el examen de casos particulares. En uso de esta facultad, cuando ha determinado la violación a un derecho reconocido en el Pacto, también ha resuelto que ello implica la existencia de la inobservancia a la obligación emanada del artículo 2.3 del mismo instrumento de proporcionar un recurso, puesto que esta disposición prevé la obligación de tomar determinadas medidas para remediar las violaciones constatadas.

En el plano regional interamericano, la Corte Interamericana de Derechos Humanos ha sido clara en el carácter autónomo del derecho a un recurso efectivo. Ello ocurrió, principalmente, en el caso Castañeda Gutman contra México, en el que pese a que la Corte declaró que no existía violación a los derechos políticos consagrados en el artículo 23 de la Convención Interamericana, se violentó el derecho a un recurso efectivo. Así, la Corte consideró que precisamente por

${ }^{17}$ Comité de Derechos Humanos de las Naciones Unidas, Casos Faneli Vs. Italia (1983), K. L. Vs. Países Bajos (1981) y Gedumbe Vs. República Democrática del Congo (1995). 
consagrar el derecho de acceso a la justicia, el artículo 25 de la Convención puede ser vulnerado independientemente de que exista o no una violación al derecho reclamado o de que la situación que le servía de sustento se encuentre dentro del campo de aplicación del derecho invocado por lo que, en razón de ello, con independencia de si la autoridad judicial declara infundado el reclamo de la persona que interpone un recurso por no estar cubierto por la norma que invoca, o no encuentra una violación del derecho que se alega vulnerado, el Estado está obligado a proveer recursos efectivos que permitan a las personas impugnar aquellos actos de autoridad que consideren violatorios de sus Derechos Humanos.

El Juez de la Corte, Eduardo Ferrer Mac Gregor, ha sostenido que en el diseño de la Convención Americana sus artículos mantienen una autonomía y contenido específico, lo que se evidencia, entre otros factores, tanto por el hecho de que cada una de las disposiciones se encuentra en artículos distintos, como por su propio lenguaje y agrega que en la jurisprudencia de la Corte se puede observar un creciente desarrollo del derecho a un recurso efectivo, además de su análisis como derecho autónomo ${ }^{18}$. Observa también que esta posición forma parte de una era jurisprudencial en que la Corte ha tratado de ser mucho más específica en describir el contenido de cada uno de los derechos y cláusulas que enmarcan a los artículos 8 y 25 del Pacto de San José, enriqueciendo con ello la jurisprudencia que en un principio englobó los múltiples y complejos derechos consagrados en los artículos 8 y 25 de la Convención Americana en la noción general del derecho de acceso a la justicia lato sensu ${ }^{19}$.

En ello ha coincidido reiteradamente el Juez Cançado Trinidade al apuntar que, en un plano esencialmente ontológico, es axiomático que cada uno de los derechos protegidos bajo los tratados de Derechos Humanos tienen contenido material propio. Sostiene que el derecho a un recurso efectivo ha tenido que pasar por una larga evolución y construcción jurisprudencial y hoy debe ser entendido y apreciado de conformidad con el principio del derecho intemporal y no de manera estática atendiendo únicamente a lo que motivó su formulación original. Agrega que desde un plano hermenéutico, el hecho de que los derechos protegidos estén dotados de contenido material propio y de autonomía no significa que no puedan, o no deban, ser

${ }^{18}$ Corte Interamericana de Derechos Humanos, caso Liakat Ali Alibux Vs. Suriname, Ob. cit. voto concurrente del Juez FERRER MAC GREGOR, Eduardo, párrafo 129.

${ }^{19}$ Corte Interamericana de Derechos Humanos, caso Manuel Cepeda Vargas Vs. Colombia (Excepciones Preliminares, Fondo y Reparaciones), sentencia de 26 de mayo de 2010. Serie C, número 213, párrafo 171. 
relacionados unos con los demás en razón de las circunstancias del cas d'espèce y que dicha interrelación es la que proporciona, a la luz de la indivisibilidad de todos los Derechos Humanos, una protección más eficaz ${ }^{20}$.

\title{
V. TRAYECTO HISTÓRICO-CONVENCIONAL DEL DERECHO A UN RECURSO EFECTIVO
}

\author{
El primer instrumento internacional en consagrar el derecho a un
} recurso efectivo ${ }^{21}$ fue la Declaración Americana de Derechos y Debe-

${ }^{20}$ Corte Interamericana de Derechos Humanos, caso de la Masacre de Pueblo Bello vs. Colombia, 248, sentencia de 31 de enero de 2006, serie C, número 140, voto razonado del Juez CANÇADO TRINDADE, Antonio Augusto, párrafo 15.

${ }^{21}$ El origen de la protección de los Derechos Humanos por la vía judicial se ubica en el concepto del due process of law del common law inglés, que es la norma según la cual los individuos no deben ser privados de su vida, libertad o propiedad sin que previamente se les brinde la oportunidad de una defensa. En Inglaterra la conciencia común de la libertad humana y su protección jurídica presionaron por el desarrollo normativo de los medios para su protección. Con la finalidad de evitar la venganza privada así como diversas formas de violencia, a instancias del rey, se instauraron los primeros tribunales o «Witan», formados por consejo de nobles que vigilaban el desarrollo de los juicios. La imposibilidad del monarca de impartir justicia en todos los lugares del reino llevó a establecer la Corte del Rey, que se encontraba sometida a una autoridad judicial central que, en general, respetaba las diversas costumbres y tradiciones jurídicas de las diversas regiones en que se desempeñaba, con lo que nació el «common law» o derecho común. Esta costumbre jurídica interpretada y definida por los tribunales era frecuentemente contravenida por el rey, lo que redundó en la exigencia y surgimiento de bills, documentos en los que se hacía constar los privilegios y que constituyen el primer precedente de derechos fundamentales. El más antiguo de estos documentos es la Carta Magna, firmada a principios del siglo XIII, por el rey Juan Sin Tierra, compelido por los barones ingleses. En uno de los preceptos más importantes, marcado con el número 46, indicaba que ningún hombre libre podía ser arrestado, expulsado o privado de sus propiedades, sino mediante juicio de sus pares y por las leyes de la tierra "per legem terrae, by the law of the land» y que «Ninguna persona, cualquiera que sea su condición o estamento, será privada de su tierra, ni de su libertad, ni desheredado, ni sometido a pena de muerte, sin que antes responda a los cargos en un debido proceso legal». Sin embargo, debido a que fue firmada bajo coacción, el rey recibió la aprobación del Papa para romper su palabra tan pronto como las hostilidades cesaran, dejando sin obligatoriedad legal el contenido de la Carta Magna que, sin embargo, influyó en que los súbditos tuvieran conciencia de que les correspondían tales derechos. El concepto de «ley de la tierra» estaba dirigido a la proteger tanto la libertad y como la propiedad y evolucionó al «due process of law» o debido proceso que implicaba una garantía de legalidad y seguridad jurídica en el sentido de que una privación de los derechos sólo podría efectuarse por una causa jurídica suficiente permitida por el derecho consuetudinario, de conformidad con la ley y mediante juicio de los pares.

Posteriormente, en la Petition of Rights de 1628, redactada por Sir Edward Coke, se invocan los estatutos y las normas del common law para solicitar y exigir su respeto al rey Carlos I, ante diversas arbitrariedades cometidas con la finalidad de recau- 
res del Hombre de abril de 1948, en su artículo XVIII. Reseña el Juez Cançado Trindade ${ }^{22}$ que la adopción del derecho a un recurso efectivo en ésta surgió de una iniciativa latinoamericana, influenciada fuertemente en los principios que rigen el recurso de amparo, ${ }^{23}$ ya entonces

dar impuestos para sufragar guerras. Este documento resulta trascendente pues en su conformación intervino el Parlamento Inglés al exhortar al rey para su cumplimiento y representó una reiteración de los principios de la Carta Magna, reafirmándose las limitaciones del poder monárquico y el imperio de la ley. Se estableció que no podrían imponerse tributos sin la aprobación del Parlamento y que nadie sería detenido o juzgado, sino en conformidad a las leyes comunes.

El siguiente documento inglés, la Bill of Rights de 1679, es producto de las guerras de religión en Inglaterra y se convirtió en el fundamento de la Constitución de Gran Bretaña, garantiza la garantía de legalidad tributaria, la prohibición de las multas o fianzas excesivas, la libre elección del Parlamento, la imposibilidad de que el rey derogue una ley, la libertad de expresión y discusión en los parlamentos, la imposibilidad de que el rey sea católico, se declara la libertad de culto y separa la política estatal de la religión; reconoce, además, el derecho de petición al rey, el de portación de armas, la libertad de tribuna en el Parlamento y la libertad en la elección de los comunes. A la par nace la figura del habeas corpus, regulada en el Habeas Corpus Amendment Act de 26 de mayo de 1679, que es considerado el primer documento en reglamentar un proceso constitucional de tutela de derechos fundamentales.

Las ideas contenidas en las cartas inglesas se reflejaron en los movimientos liberales de fines del siglo XVIII, influyendo en la Guerra de Independencia de los Estados Unidos de América que concluyó con la Declaración de Independencia Norteamericana y la Declaración de Derechos de Virginia de 1776; así como en la Revolución Francesa que derivó en la Declaración de los Derechos del Hombre y del Ciudadano de 1789. Estos antecedentes sirvieron de basamento para formulación de la Constitución de los Estados Unidos de América, la Constitución Francesa (1791) y, posteriormente, para el resto de las constituciones modernas de occidente. (Ver: BURGOA, Ignacio. Las Garantías Individuales, Porrúa, México, 1995, edición 27, pág. 85; LARA PONTE, Rodolfo. «Los Derechos Humanos en el Constitucionalismo Mexicano» en Estudios Doctrinales, número 151, serie G, Instituto de Investigaciones Jurídicas de la UNAM, México, 1993, págs. 27 y 28; PACHECO G., Máximo. Los Derechos Humanos. Documentos Básicos, Jurídica de Chile, Santiago, 1992, págs. 1-11).

${ }^{22}$ Corte Interamericana de Derechos Humanos. Caso de la Masacre de Pueblo Bello Vs. Colombia, Ob. cit. voto razonado del Juez CANÇADO TRINDADE, Antonio Augusto, párrafos 17 y ss.

${ }^{23}$ El Amparo es una figura de construcción original mexicana, adoptada por primera vez en la Constitución de la República de Yucatán el 16 de mayo de 1847, que tiene su antecedente apoyo en el proyecto elaborado en diciembre del año anterior por una comisión encabezada por el ilustre jurista y político Manuel Crescencio Rejón que, además, se trata del primer recurso en consagrar, derivado de la tradición jurídica anglosajona y del sistema constitucional norteamericano, la revisión judicial de la constitucionalidad de los actos de autoridad en América Latina. Posteriormente, a través del Acta de Reformas a la Constitución Federal de 1824, promulgada el 21 de mayo de 1847, según el proyecto elaborado por Manuel Otero, se consagra, en el artículo 25, a nivel constitucional mexicano el juicio de según el cual «Los tribunales de la Federación ampararán a cualquier habitante de la República en el ejercicio y conservación de los derechos que le conceda esta Constitución y las leyes constitucionales contra todo ataque de los poderes legislativo y ejecutivo, ya de la Federación, ya de los Estados; limitándose dichos tribunales a impartir su protección en el caso particular sobre que verse el proceso, sin hacer ninguna declaración general respecto

(C) UNED. Revista de Derecho UNED, núm. 17, 2015 
consagrado en las legislaciones nacionales de varios países de la región, por lo que la redacción del artículo XVIII fue adoptada por unanimidad de las veintiún delegaciones presentes.

La influencia del amparo mexicano en la redacción del artículo XVIII de la Declaración Americana de Derechos y Deberes del Hombre es clara, pues éste prevé el derecho de toda persona de disponer de un procedimiento sencillo y breve por el cual la justicia lo proteja contra actos de autoridad que violen alguno de los derechos fundamentales. Esta disposición fue posteriormente adoptada en la Declaración Universal de los Derechos Humanos. El proyecto de esta declaración fue preparada en el seno de la Comisión de Derechos Humanos de Naciones Unidas por un grupo de trabajo entre mayo de 1947 y junio de 1948 y presentado en septiembre de 1948 ante la III Comisión de la Asamblea General de Naciones Unidas a fin de que fuera finalmente aprobado el 10 de diciembre del mismo año ${ }^{24}$.

Del contenido de las actas y documentos de la Conferencia Especializada Interamericana sobre Derechos Humanos, que recoge los trabajos preparatorios de la Convención Interamericana de Derechos Humanos, se hace evidente que el antecedente del derecho a un recurso efectivo es la figura del recurso de amparo mexicano. En el registro de la intervención del Presidente de la Comisión «I», grupo responsable del debate del actual artículo 25, expresó que el proyecto de artículo suponía la consagración del clásico derecho de amparo ${ }^{25}$. La Corte

de la ley o del acto que la motivare». Esta figura fue incorporándose poco a poco en los sistemas jurídicos latinoamericanos, adoptándolo primeramente la República de El Salvador en el año de 1886, después Honduras y Nicaragua, en 1894; Guatemala y Argentina en 1921; Panamá en 1941; Costa Rica en 1949; Venezuela en 1961; Bolivia y Paraguay en 1967; Perú en 1979 y Uruguay en 1984. Además el derecho de amparo, como instrumento protector de los derechos fundamentales, fue incorporado a la Constitución Española Republicana de 1931 y, después, en la Carta Democrática de diciembre de 1978 y posee un gran desarrollo jurisprudencial. (Ver: NOGUEIRA ALCALÁ, Humberto (2003). Teoría y Dogmática de los Derechos Fundamentales, serie doctrina jurídica, número 156, Instituto de Investigaciones Jurídicas de la UNAM, México, 2003 y FIX-ZAMUDIO, Héctor. «Avances y perspectivas de la protección procesal de los derechos humanos en Latinoamérica» en Protección Jurídica de los Derechos Humanos. Estudios Comparativos, CNDH, segunda edición, México, 1999, p. 422).

${ }^{24} C f r$. CANÇADO TRINDADE, Antonio Augusto. Tratado de Derecho Internacional de los Derechos Humanos, volumen I, Fabris, Porto Alegre, Brasil, 2003, segunda edición, págs. 51-77.

${ }^{25}$ Organización de Estados Americanos, Comisión Interamericana de Derechos Humano, Documentos Básicos de Derechos Humanos en el Sistema Interamericano, Actas y Documentos de la Conferencia Interamericana sobre Derechos Humanos de 1969 (trabajos preparatorios o travaux préparatoires) donde se adoptó la Convención Americana sobre Derechos Humanos, Conferencia Especializada Interamericana sobre Derechos Humanos. Actas y Documentos, San José, Costa Rica, 7-22 de noviem- 
Interamericana también ha reconocido que su texto «es una disposición de carácter general que recoge la institución procesal del amparo, entendido como el procedimiento judicial sencillo y breve que tiene por objeto la tutela de todos los derechos reconocidos por las constituciones y leyes de los Estados Partes y por la Convención ${ }^{26}$.

El Juez Cançado Trindade comenta que la disposición contenida en el artículo 8 de la Declaración -según la cual toda persona tiene derecho a un recurso efectivo ante los tribunales nacionales competentes contra los actos violatorios de los derechos fundamentales- fue agregada a iniciativa de las delegaciones de los Estados latinoamericanos durante la etapa final de los trabajos preparatorios. En ese momento el dispositivo en cuestión se encontraba todavía bajo examen en la III Comisión de la Asamblea General de Naciones Unidas. Relata que la propuesta significativamente no encontró objeción alguna, habiendo sido aprobado por 46 votos a cero y tres abstenciones en el seno de la Comisión. Posteriormente, fue votada en el plenario de la Asamblea General por unanimidad. Concluye que el derecho a un recurso efectivo representa la contribución latinoamericana par excellence a la Declaración Universal.

En el proyecto original, el actual artículo 25 de la Convención, que antes se identificaba con el número 23 , se componía de un único párrafo, al que se añadió otro para puntualizar los compromisos del Estado al respecto; además, la primera versión de esta disposición se limitaba a consagrar la protección judicial sólo para los derechos establecidos en la Constitución y las leyes del país respectivo, pero durante los trabajos preparatorios la representación del gobierno de Chile planteó que tal redacción resultaba insuficiente al no referirse a los derechos reconocidos por la Convención y propuso la respectiva modificación sobre la base de la formulación del citado artículo 2.3 del Pacto Internacional de Derechos Civiles y Políticos que incluye las tres obligaciones estatales establecidas en el hoy artículo 25.2 de la Convención la cual fue finalmente aprobada ${ }^{27}$. El argumento básico que llevó a la inserción de esta disposición en la Declaración Americana consistió en que se debía reconocer la existencia una laguna,

bre de 1969, OEA/Ser. K/XVI/1.2, p. 261 en http://www.oas.org/es/cidh/mandato/Basicos/actas-conferencia-interamericana-Derechos-Humanos-1969.pdf

${ }^{26}$ Corte Interamericana de Derechos Humanos, El Hábeas Corpus bajo Suspensión de Garantías (arts. 27.2, 25.1 y 7.6 Convención Americana sobre Derechos Humanos), Opinión Consultiva OC-8/87 del 30 de enero de 1987, serie A, número 8, párrafo 32 y Garantías Judiciales en Estados de Emergencia (Arts. 27.1, 25 y 8 de la Convención Americana Sobre Derechos Humanos), opinión consultiva OC-9/87, Ob. cit., párrafo 23.

${ }^{27}$ Conferencia Especializada Interamericana sobre Derechos Humanos, Actas y Documentos, Ob. cit. pág. 22. 
puesto que no existía la obligación de proteger los derechos del individuo contra los abusos del poder público, por lo que se hacía necesario someter todo y cualquier abuso de todos los derechos individuales al juicio del Poder Judicial en el plano de derecho interno ${ }^{28}$.

Así, la consagración original del derecho a un recurso efectivo ante los jueces o tribunales nacionales competentes en la Declaración Americana (artículo XVIII) fue trasplantada a la Declaración Universal (artículo 8) y, de esta última, a las Convenciones Europea y Americana sobre Derechos Humanos (artículos 13 y 25, respectivamente) y en el Pacto de Derechos Civiles y Políticos de las Naciones Unidas [artículo 2(3)] y representa «la posibilidad real de acceder a un recurso judicial para que la autoridad competente y capaz de emitir una decisión vinculante determine si ha habido o no una violación a algún derecho que la persona que reclama estima tener y que, en caso de ser encontrada una violación, el recurso sea útil para restituir al interesado en el goce de su derecho y repararlo» ${ }^{29}$.

\section{CONCEPTUALIZACIÓN Y CARACTERIZACIÓN DEL DERECHO A UN RECURSO EFECTIVO}

Los derechos subjetivos concedidos a los individuos oponen y limitan el derecho objetivo de que hacen uso los poderes estatales. Sin embargo es necesaria la existencia de medios de protección y defensa a los Derechos Humanos, a fin de que exista la posibilidad de limitación del poder público. Es una realidad que el Estado con su accionar constantemente vulnera los Derechos Humanos reconocidos, por lo que, una vez que éstos se han incorporado a un sistema jurídico, surge la obligación por parte del Estado de crear un marco jurídico de protección que incluya un control de constitucionalidad y/o convencionalidad de los actos violatorios de Derechos Humanos, el resarcimiento de daños y el establecimiento de responsabilidades.

En la concepción actual del Estado es trascendental la sumisión del poder al derecho, lo cual únicamente es posible si existen los ins-

${ }^{28}$ Corte Interamericana de Derechos Humanos. caso de la Masacre de Pueblo Bello Vs. Colombia, Ob. cit., voto razonado del Juez CANÇADO TRINDADE, Antonio Augusto, párrafos 61 y 18 .

${ }^{29}$ Corte Interamericana de Derechos Humanos, Garantías Judiciales en Estados de Emergencia (Arts. 27.1, 25 y 8 de la Convención Americana Sobre Derechos Humanos), opinión consultiva OC-9/87, Ob. cit., párrafo 24; Caso Castañeda Gutman Vs. Estados Unidos Mexicanos (Excepciones Preliminares, Fondo, Reparaciones y Costas), Ob. cit. párrafo 100 y Caso Pueblo Indígena Kichwa de Sarayaku Vs. Ecuador (Fondo y reparaciones), sentencia de 27 de junio de 2012. Serie C, número 245, párrafo 261. 
trumentos legales necesarios para hacer efectivo el ejercicio de los Derechos Humanos, lo que se hace realidad mediante el control de la legalidad de los actos de los órganos que ejercen el poder. Según el principio de legalidad, ninguna autoridad puede realizar un acto para el cual no se encuentre expresamente facultado por la ley, lo que a su vez supone una garantía para los particulares. Según Pedro Nikken, Director del Instituto Interamericano de Derechos Humanos, las garantías de respeto a los Derechos Humanos comportan, en primer lugar, que todo ciudadano disponga de medios judiciales sencillos y eficaces para la protección de sus derechos y, en consecuencia, que las violaciones a los Derechos Humanos sean reputadas como ilícitas por el derecho interno, a procurar el restablecimiento del derecho violentado mediante la reparación de los daños causados, así como la investigación de los hechos para el establecimiento de la verdad y la identificación y sanción de los servidores públicos causantes de la violación ${ }^{30}$.

En esta tesitura, el distinguido constitucionalista Héctor Fix-Zamudio, señala que no es suficiente la consagración de los Derechos Humanos en los textos constitucionales para que su eficacia quede asegurada en la práctica, sino que se requiere del establecimiento de instrumentos procesales para prevenir o reparar la violación de los derechos $^{31}$. Idea que es compartida por Norberto Bobbio ${ }^{32}$ al sostener que el problema de fondo relativo a los Derechos Humanos no es hoy tanto el de justificarlos, como el de protegerlos, lo que se traduce en un problema no filosófico, sino político y agrega que: «...El problema real que se nos presenta es el de las medidas pensadas y pensables para su efectiva protección. Es inútil decir que nos encontramos en un camino inaccesible y en el que, además, se encuentran por lo menos dos tipos de caminantes: los que ven claro pero tienen los pies atados y los que tendrían los pies libres pero ¡ay!, tienen los ojos vendados. Ante todo me parece que es preciso distinguir dos órdenes de dificultades, una de naturaleza propiamente más jurídico-política y otra sustancial, es decir, inherente el contenido de los derechos en cuestión».

${ }^{30}$ Cfr. NIKKEN, Pedro. «El Concepto de Derechos Humanos» en Estudios Básicos de Derechos Humanos, Instituto Interamericano de Derechos Humanos, San José, 1994, págs. 1-6 en http://www.disaster-info.net/desplazados/Venezuela/documentos/ konrad/recopdh03concepto.htm.

${ }^{31} C f r$. FIX-ZAMUDIO, Héctor. «Protección Procesal de los Derechos Humanos» en Protección Jurídica de los Derechos Humanos. Estudios Comparativos, Ob. cit., pág. 26.

${ }^{32}$ BOBBIO, Norberto. El tiempo de los derechos, p. 61 citado por GUERRERO, Ana Luisa. Filosofía política y derechos humanos, UNAM, México, 2002, pág. 20. 
El derecho a un recurso efectivo constituye el derecho humano para acceder a cualquier mecanismo establecido en ley para la protección de los derechos o libertades que se consideran violentados. El Instituto Interamericano de Derechos Humanos ha definido al recurso efectivo como mecanismo de acceso a la justicia como «la posibilidad de que cualquier persona, independientemente de su condición, tenga la puerta abierta para acudir a los sistemas de justicia si así lo desea... a sistemas, mecanismos e instancias para la determinación de derechos y la resolución de conflictos». ${ }^{33}$ Esta definición pone de manifiesto las diversas dimensiones incluidas en su concepción ya que se constituye como un derecho en sí mismo, en garantía de protección y cumplimiento de otros Derechos Humanos e implica un deber a cargo del Estado de establecer los medios para hacerlo efectivo.

En este orden, el derecho de acceso a la justicia puede identificarse con las siguientes concepciones: Es un valor constitucional conforme a la convivencia social y pacífica de mantener la concordia nacional y de asegurar la integridad de un orden político, económico, jurídico y social justo, mediante la regulación estatal de las relaciones de la persona con un trasfondo axiológico que conlleve a satisfacer esta cualidad. Por otra parte, representa la obligación a cargo del Estado de prestar un buen servicio al administrar justicia en un proceso en el que se esté en la posibilidad de hacer uso de las herramientas procesales previstas por la ley, que se cautele provisionalmente y que concluya con un pronunciamiento razonado y en breve plazo que solucione el conflicto planteado. Y, también, se traduce en un concepto estructural y organizacional relativo a los órganos que administran justicia, lo que implica un conjunto de instancias, recursos y organismos en que se tramitan los procesos, así como también la provisión de los servicios jurídicos gratuitos de asesoría legal y la posibilidad de dirimir las controversias en mecanismos alternos de solución. ${ }^{34}$

Según Sánchez Gil, el derecho a un recurso efectivo consiste en «la facultad que tienen las personas de recurrir a los órganos jurisdiccionales para obtener de ellos la tutela de sus derechos y no quedar

${ }^{33}$ Instituto Interamericano de Derechos Humanos, Guía informativa, XVIII Curso Interdisciplinario en Derechos Humanos, p. 17 citado por SAGÜÉS, María Sofía. El acceso a la justicia en el Sistema Interamericano de Protección de Derechos Humanos. Proyección en la Jurisdicción Constitucional en Biblioteca Jurídica Virtual del Instituto de Investigaciones Jurídicas de la UNAM http://biblio.juridicas.unam.mx/libros/6/2562/27.pdf,

${ }^{34}$ ARAÚJO-OÑATE, Rocío Mercedes. «Acceso a la justicia efectiva. Propuesta para fortalecer la justicia administrativa. Visión de derecho comparado" en Revista de Estudios Socio-jurídicos, número 13, enero-junio, Universidad del Rosario, Bogotá, 2011, págs. 247-291. 
desprotegidos ante su violación». ${ }^{35}$ Implica, entonces, la posibilidad de que cualquier persona ejercite los mecanismos legalmente previstos para la protección y el restablecimiento de los derechos consagrados tanto en las constituciones locales, como en tratados internacionales.

\section{A. Es un derecho humano autónomo de tipo público subjetivo}

La ratificación de un tratado internacional en materia de Derechos Humanos por un Estado le obliga a crear los medios para hacer valer las acciones judiciales que permitan al titular de los derechos afectados ante una autoridad judicial, u otra con similar independencia, recurrir la falta de respeto a ése. Entonces, implica el reconocimiento $\mathrm{u}$ otorgamiento de un campo de poder. ${ }^{36}$ Este campo de poder representa, a su vez, un derecho público subjetivo en sí mismo, pues otorga a los ciudadanos la titularidad de ejercitar una acción a fin de exigir una prestación a los Poderes del Estado.

Según Miguel Carbonell, el derecho a un recurso efectivo tiene un carácter adjetivo, no sustantivo, ya que no protege directamente algún interés de la persona en particular, sino que les concede la posibilidad de tener una vía jurisdiccional mediante la cual puede lograr el respeto de sus intereses de cualquier índole, que pueden estar protegidos por normas de diferente rango jerárquico. ${ }^{37}$ En contradicción a esta postura, la jurisprudencia constante del Sistema Interamericano, con una visión más moderna y garantista, considera que el derecho a un recurso efectivo tiene el carácter de autónomo, cuyo incumplimiento genera per se una violación a los Derechos Humanos, por lo que se constituye como un derecho subjetivo en sí mismo.

También la evolución interpretativa del derecho a un recurso efectivo en la jurisprudencia de la Corte Europeo de Derechos Humanos

${ }^{35}$ SÁNCHEZ GIL, Rubén. «El derecho de acceso a la justicia y el amparo mexicano» en Revista Iberoamericana de Derecho Procesal Constitucional. Proceso y Construcción, año V, núm. 4, julio-diciembre, Porrúa-Instituto Iberoamericano de Derecho Procesal Constitucional, México, 2005, pág. 240.

${ }^{36}$ Organización de Estados Americanos, Comisión Interamericana de Derechos Humanos, El Acceso a la Justicia como Garantía de los Derechos Económicos, Sociales y Culturales, Estudio de los Estándares fijados por el Sistema Interamericano de Derechos Humanos, OEA/Ser. L/V/II.129 Doc. 4, 7 septiembre 2007, Original: español, párrafo 236.

${ }^{37}$ CARBONELL, Miguel. Los derechos fundamentales en México, CNDH-Instituto de Investigaciones Jurídicas de la UNAM, México, 2004, pág. 726. 
ha derivado en reconocer que el Estado de Derecho no puede estar desasociado del imperio de la ley en una sociedad democrática, del cual forma parte integrante el derecho a un recurso efectivo. El contenido material de éste lo distingue como un derecho subjetivo y autónomo, caracterizado, además de representar como una herramienta indispensable en la protección de los derechos del hombre ${ }^{38}$.

Cuando se ejercita el derecho a la tutela judicial efectiva (lato sensu) mediante la interposición de un recurso efectivo (stricto sensu), se puede distinguir entre el derecho que se pretende hacer valer (subjetivo material) y el derecho mediante el cual se hace valer (derecho procesal o adjetivo). El derecho a un recurso efectivo anteriormente era considerado como un derecho adjetivo y ahora se puede decir que tiene el carácter de derecho subjetivo procesal ${ }^{39}$, pero es innegable que tiene substancia por sí mismo. Este derecho humano tiene, además, el carácter de ius cogens puesto que las normas que lo rigen son de índole imperativo e independientes de la voluntad de las partes, por lo que no es posible su derogación de un orden jurídico y no puede ser modificado voluntariamente y, por tanto, todo compromiso en contrario representa per se una violación ${ }^{40}$.

El carácter de ius cogens del derecho a un recurso efectivo conlleva a su irrenunciabilidad pues los derechos humanos no pueden ser objeto de convención, negociación o renuncia ${ }^{41}$. Las características de inalienabilidad e irrenunciabilidad de los derechos humanos hacen que no puedan ser objeto de contrato alguno que impida su ejercicio. En este sentido cualquier cláusula o manifestación en contrario debe tenerse como no puesta, conforme a lo establecido en el artículo 30 de la Convención Americana sobre Derechos Humanos que señala que las restricciones a los derechos y libertades únicamente pueden ser aplicadas conforme a las leyes dictadas por razones de interés general. ${ }^{42}$

${ }^{38}$ HARRIS, David (et. al.). Law of the European Convention on Human Rights, Butterworths, Londres, 1995, p. 461.

${ }^{39}$ TOSCANO LÓPEZ, Fredy Hernando. «Una aproximación conceptual al acceso efectivo a la administración de justicia a partir de la teoría de la acción procesal (A Conceptual Approach to the 'Effective Access to Justice' in the Procedural Action Theory)» en Revista de Derecho Privado, número 24, Instituto de Investigaciones Jurídicas de la UNAM, México, 2013, en http://ssrn.com/abstract=2306296.

${ }^{40}$ MARABOTTO LUGARO, Jorge A. Un derecho humano esencial: el acceso a la justicia en Biblioteca Jurídica Virtual del Instituto de Investigaciones Jurídicas de la UNAM, http://juridicas.unam.mx/publica/librev/rev/dconstla/cont/2003/pr/pr16.pdf.

${ }^{41}$ Cabe referir que en muy diversas ocasiones el Estado obliga a los particulares a firmar convenios en los que se obligan a no ejercitar los medios de defensa que las leyes le conceden.

${ }^{42}$ Convención Americana sobre Derechos Humanos:

Artículo 30. Alcance de las Restricciones 


\section{B. Como instrumento para hacer efectivos otros derechos}

El derecho de acceso a la justicia tiene un carácter instrumental, pues a través de su ejercicio es factible la exigencia de respeto a otros Derechos Humanos, es decir, de éste derivan los mecanismos mediante los cuales los segundos son justiciables y, en este sentido, representa el mecanismo que sirve para asegurar, proteger y dar certeza a todos los derechos reconocidos en determinado orden nacional. Este carácter lleva consigo a que el derecho a un recurso efectivo se constituya como el medio de protección a los Derechos Humanos en contra de cualquier acto que de alguna manera los afecte y representa la posibilidad de dirimir el cumplimiento de derechos y obligaciones recíprocas con el Estado.

El Programa de Naciones Unidas para el Desarrollo lo conceptualiza como un derecho humano básico y un medio indispensable para combatir la pobreza, prevenir y resolver conflictos y considera que existen fuertes vínculos entre el establecimiento de un gobierno democrático, la reducción de la pobreza y el aseguramiento de acceso a la justicia. Mauro Cappelleti y Bryant Garth representan esta concepción indicando que es el «más fundamental» de todos los derechos, ya que los éstos no tendrían efectividad alguna de no existir el modo por el cual remediar su violación ${ }^{43}$.

En efecto, la posibilidad jurídica de hacer valer un recurso ante una violación de los Derechos Humanos permite asegurar su máximo grado de disfrute ${ }^{44}$, así «Tomar en serio lo dispuesto por el artículo 25 de la Convención Americana nos llevaría a establecer la obligatoriedad de que se dispongan de recursos judiciales efectivos y que en esos recursos se vigile no sólo el cumplimiento de las leyes, sino también lo dispuesto por la Constitución, del país que se trate, y de la propia Convención Americana. Se trata del derecho a la garantía de los derechos fundamentales» ${ }^{45}$.

Las restricciones permitidas, de acuerdo con esta Convención, al goce y ejercicio de los derechos y libertades reconocidas en la misma, no pueden ser aplicadas sino conforme a leyes que se dictaren por razones de interés general y con el propósito para el cual han sido establecidas.

${ }^{43}$ CAPPELLETTI, Mauro y GARTH, Bryant. El acceso a la justicia. La tendencia en el movimiento mundial para hacer efectivos los derechos, trad. de Mónica Miranda, Fondo de Cultura Económica, México, 1996, págs. 12-13.

${ }^{44}$ CASTILLA JUÁREZ, Karlos Artemio. Acceso Efectivo a la Justicia, elementos y caracterización, Editorial Porrúa, México, 2012, pág. 45.

${ }^{45}$ Corte Interamericana de Derechos Humanos, Caso Liakat Ali Alibux Vs. Suriname, Ob. cit. voto concurrente del Juez FERRER MAC GREGOR, Eduardo, párrafo 71. 
Este carácter de derecho-garantía cobra especial importancia dentro de un modelo de control de convencionalidad. El control de convencionalidad es, en palabras de la propia Corte Interamericana, «una institución que se utiliza para aplicar el Derecho Internacional, en este caso el Derecho Internacional de los Derechos Humanos, y específicamente la Convención Americana y sus fuentes, incluyendo la jurisprudencia de este Tribunal» ${ }^{46}$. Este instrumento permite que los jueces nacionales se erijan como efectivos garantes de los Derechos Humanos, lo que conlleva que la violación de los Derechos Humanos encuentre su remedio en la sede interna de los Estados y no lleguen continuamente casos sobre el mismo tema a la Corte Interamericana.

Reitera el juez Mac Gregor que el ejercicio de un control de convencionalidad se da, por una parte, en la interpretación sustantiva de los derechos de la Convención Americana y, por otra, en que los Estados se encuentren obligados a cumplir con los requerimientos procesales mínimos dispuestos dentro del derecho a la protección judicial, según lo establece el artículo 25 de la Convención. El cumplimiento de esta obligación fortalece el derecho a un recurso efectivo para que los demás derechos puedan ser garantizados y, en consecuencia, protegidos en sede judicial ${ }^{47}$.

\section{C. Como especie dentro del género de los derechos de seguridad jurídica}

Es posible clasificar a los Derechos Humanos con relación al bien jurídico que tutelan en cuatro géneros: de propiedad, de igualdad, de libertad y de seguridad jurídica. ${ }^{48}$ Las garantías de igualdad tienen como fundamento la idea de que todo ser humano tiene derecho a la protección de la ley de acuerdo a sus atributos y condiciones individuales, protección a la que se debe acceder sin discriminación alguna y las garantías de la libertad tienen una doble finalidad: la primera, física, relativa a garantizar los derechos básicos a la vida, a las propiedades y a no ser aprisionado sin un juicio en el que se respeten las

${ }^{46}$ Corte Interamericana de Derechos Humanos, Caso Gelman Vs. Uruguay. (Supervisión de Cumplimiento de Sentencia), resolución de 20 de marzo de 2013, serie C, número 221, párrafo 65 .

${ }^{47}$ Corte Interamericana de Derechos Humanos, Caso Liakat Ali Alibux Vs. Suriname, Ob. cit. voto concurrente del Juez FERRER MAC GREGOR, Eduardo, párrafo 89.

${ }^{48}$ LARA PONTE, Rodolfo. Los derechos humanos en el constitucionalismo mexicano, Porrúa, México, 1997 citado por ORTIZ TREVIÑO, Rigoberto Gerardo. La Seguridad Jurídica, los derechos humanos en la jurisprudencia mexicana, CNDH, México, 2004, pág. 50. 
formalidades esenciales del procedimiento; pero también otra intelectual o espiritual, que es la que la Corte Interamericana de Derechos Humanos ha identificado como el derecho a un proyecto de vida, que es el derecho de autodeterminación, de planear y gozar de una existencia fuera de la interferencia violatoria del Estado. Por último, las garantías de seguridad jurídica ${ }^{49}$ tienen a la protección de estos derechos y libertades que se pueden definir como «el conjunto general de condiciones, requisitos, elementos o circunstancias previas a que debe sujetarse una cierta actividad estatal autoritaria para generar una afectación válida de diferente índole en la esfera del gobernado, integrada por el summum de sus derechos subjetivos». ${ }^{50}$

Los derechos subjetivos son tutelados por las garantías de seguridad jurídica que no son materiales sino formales, esto es, susceptibles de operar en forma de protección sobre cualquier derecho subjetivo del gobernado. Entre dichas garantías de seguridad jurídica se encuentra el derecho a un recurso efectivo en tanto que asegura que las autoridades se apegarán a las disposiciones legales en su actuar y si con ello se produce una afectación a los derechos de los particulares, procederá la interposición del recurso previsto en la ley a fin de restablecer el derecho o libertad infringida y reparar las consecuencias de la violación. La Corte Interamericana de Derechos Humanos se ha pronunciado en el sentido de que es un principio del Derecho Internacional, que la jurisprudencia ha considerado «incluso una concepción general de derecho», que toda violación a una obligación internacional que haya producido un daño comporta el deber de repararlo adecuadamente y que la indemnización, constituye la forma más usual de hacerlo, más no la única. ${ }^{51}$ La reparación que se debe a las víctimas o a sus familiares debe estar orientada a procurar la total restitución de los daños causa-

${ }^{49}$ De acuerdo con la Suprema Corte de Justicia de la Nación de México, la seguridad jurídica «es la certeza que debe tener el gobernado de que su persona, su familia, sus posesiones o sus derechos serán respetados por la autoridad, pero si ésta debe producir una afectación en ellos, deberá ajustarse a los procedimientos previamente establecidos en la Constitución Política de los Estados Unidos Mexicanos y las leyes secundarias» y define a las garantías de seguridad jurídica como aquellos «derechos subjetivos públicos a favor de los gobernados, que pueden ser oponibles a los órganos estatales, a fin de exigirles que se sujeten a un conjunto de requisitos previos a la comisión de actos que pudieran afectar la esfera jurídica de los individuos, para que éstos no caigan en la indefensión o la incertidumbre jurídica, lo que hace posible la pervivencia de condiciones de igualdad y libertad para todos los sujetos de derechos y obligaciones» (Ver: Suprema Corte de Justicia de la Nación, Las Garantías de Seguridad Jurídica. Colección Garantías Individuales, México, 2003, pág. 9).

${ }^{50}$ BURGOA, Ignacio, Ob. cit., p. 502.

${ }^{51}$ Corte Interamericana de Derechos Humanos: Caso Velásquez Rodríguez Vs. Honduras (Reparaciones y costas), sentencia de 21 de julio de 1989, serie C, número 07, párrafo 25. 
dos por el hecho violatorio de los Derechos Humanos que debe incluir los conceptos de justa restitución, en caso de que la reparación no sea posible, la rehabilitación, la indemnización y las medidas de no repetición. La indemnización, a su vez, se divide en daño emergente, lucro cesante, daño moral y daños punitivos.

\section{CONCLUSIONES}

Niklas Luhmann sostiene que «la validez de la norma se muestra en su violación», lo cual resulta en una paradoja que reside en el hecho de que los derechos humanos son tanto más conocidos y afirmados cuanto más graves y frecuentes son las violaciones a los mismos. Es posible utilizar esta afirmación para cuestionar la fortaleza de un sistema jurídico, que es puesta a prueba ante la violación de un derecho humano al comprobarse la existencia (o inexistencia) de las consecuencias de ésa violación.

En este orden de ideas, el Derecho a un Recurso Efectivo impacta en el aseguramiento de un orden jurídico en dos formas de igual importancia: la seguridad y la justicia, pues se constituye en la vía para hacer efectivo el respeto a los Derechos Humanos y representa una forma de control constitucional, convencional y de legalidad de la actividad estatal en su conjunto. La importancia del Derecho a un Recurso Efectivo es que asegura no sólo plena realización de los Derechos Humanos, sino que además se configura como un mecanismo de control al poder público. Así lo sostuvo la Corte Interamericana, en el caso Castillo Páez versus Perú, al expresar que la disposición del artículo 25, sobre el derecho a un recurso efectivo ante los jueces o tribunales nacionales competentes, «constituye uno de los pilares básicos, no sólo de la Convención Americana, sino del propio Estado de Derecho en una sociedad democrática en el sentido de la Convención». 